\section{Doubts and uncertainties slow NASA's schedule}

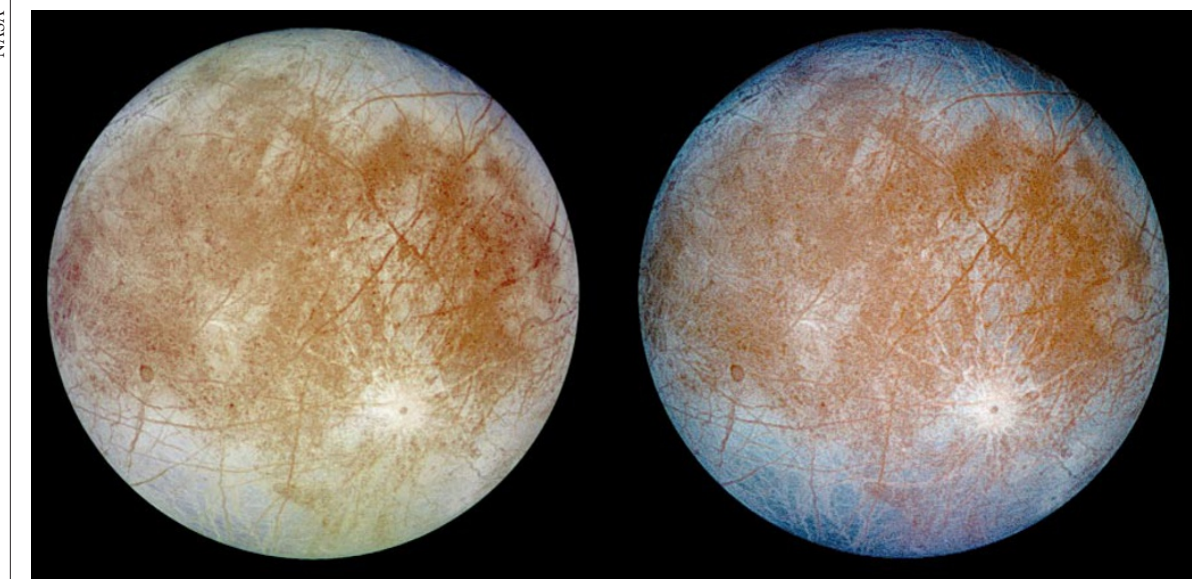

A late launch: the next mission to Europa (shown in natural, left, and false colour) faces delays.

\section{Washington}

In NASA's struggle to balance 'better, faster and cheaper', faster is starting to lose out. The space agency is considering delaying the launch dates for a number of high-profile missions on its wish list — including an orbiter to explore Jupiter's icy moon Europa.

The Jet Propulsion Laboratory (JPL) in Pasadena, which is planning the Europa project, has recommended that the launch date be moved from November 2003 to no earlier than January 2006. This rescheduling has been forced by uncertainties about the spacecraft's launch vehicle and some of the new technologies it will require.

Placing a spacecraft in orbit around one of Jupiter's moons is more difficult than orbiting the planet, and requires a heavier version of today's Delta or Atlas rockets. The US military has contracted industry to build these so-called evolved expendable launch vehicles. But development is behind schedule, and NASA would like to see several launch successes before entrusting its oneof-a-kind Europa spacecraft to a new vehicle.

Also running behind schedule is the Department of Energy's effort to develop an advanced version of the plutonium-fuelled batteries that powered the Voyager, Galileo, and Cassini spacecraft. These batteries are essential for any mission to the outer Solar System. The department recently abandoned one battery design for another, and is not expected to have a working version ready before the 2006 launch opportunity.

Even if these problems are solved, the Europa mission will still be "very, very challenging, about the hardest thing we're trying to do," says Richard Terrile, chief scientist for JPL's outer planets programme. The radiation environment at Europa will be fierce, worse than a satellite in Earth's ionosphere would endure following an all-out nuclear war. The orbiter's productive lifetime will be limited to about a month as a result.

If the Europa launch slips, the PlutoKuiper Express, a fly-by of the Solar System's last unexplored planet, would presumably move ahead in the queue to launch in December 2004 as the first in NASA's new line of outer planets missions. Unlike the Europa orbiter, the Pluto mission has a time constraint. If it waits until 2006, the less favourable planetary alignment nearly doubles its eight-year flight time.

The proposed delay to the Europa mission is all the more disappointing now that scientists are gaining confidence that an ocean really does exist there. The Europa orbiter would probe the suspected ocean with an ice-penetrating radar. Where there is liquid water there may also be life, and a National Research Council panel concluded recently that Europa was as worthy a scientific target as Mars for spacecraft exploration. With the proposed slip, the orbiter data will not come back until 2009 at the earliest.

Nor is it certain that the space agency can afford to launch both the Pluto and Europa missions within two years of each other. Following the loss of two Mars spacecraft, NASA is coldly assessing the technical and budgetary risks of all its projects, and reconsidering what it can afford. "I think we're all taking a step back," says Terrile. Before the recent reassessment, the Europa mission had been "on the path to making similar types of errors" as the doomed Mars project, he says.

Ken Nealson, JPL project scientist for the planned Mars Sample Return mission, said last week that although nothing has been decided, the first launch of a sample return mission will probably not happen until late 2008 - six years later than what was planned only a few months ago.

Tony Reichhardt

http://www.jpl.nasa.gov/ice_fire

\section{Spain gives science and technology a ministry of its own}

\section{Barcelona}

Spain's re-elected prime minister, José Maria Aznar, announced the creation of a new Ministry of Science and Technology last week. He said that this was a response to the need for research, innovation and the 'technological revolution' to be at the heart of the new government.

The ministry will be responsible for policy on basic and applied research, information technology and telecommunications. It will also gather those research activities that had been spread among other ministries, and will incorporate the country's Higher Council of Scientific Research.

César Nombela, the council's president, says: "the creation of the Ministry of Science and Technology is great news for the Spanish scientific community."

The ministry's policy on basic and applied research will follow the strategic 'action lines' set out in the National Plan on Research, Development and Technological Innovation 2000-04 (see Nature 402, 223-224; 1999). The government intends to use this plan to identify research areas in which Spain can be more competitive.

The new minister is Anna Birulés, an economist and, since 1997, directorgeneral of the telecommunications giant Retevisión. She was previously vicepresident in the Department of Industry of Catalonia's regional government.

The Ministry of Education and Culture, which had been responsible for science and higher education, will be led by Pilar del Castillo, president of the government's Centre for Sociological Investigation since 1996.

The government believes that Spain's social and economic situation makes this the right moment to attempt to raise support for research to the level of most developed countries. Achieving this goal will require close collaboration with the private sector: one of the science ministry's first tasks will be to create a biomedical research fund with the pharmaceutical industry.

In his investiture speech to parliament on 25 April, Aznar said: "[Spain] has to end the traditional weakness of its scientific and technological system". He added that the government wants the proportion of gross national product spent on research and development to rise from 0.9 per cent to 2 per cent by the end of the parliament. 